\title{
Relation between coronary anatomy and serial changes in left ventricular function on exercise: a study using first pass radionuclide angiography with gold-195m
}

\author{
JOHN L CAPLIN, DUNCAN S DYMOND, JAMES C O'KEEFE,

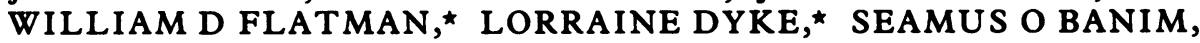 \\ ROWORTH A J SPURRELL
}

From the Departments of Cardiology and ${ }^{\star} N u c l e a r$ Medicine, St Bartholomew's Hospital, London

SUMMARY Serial changes in left ventricular function on exercise were assessed by first pass radionuclide angiography with gold-195m (half life $30.5 \mathrm{~s}$ ) in 25 men with known coronary anatomy. In the seven patients with three vessel disease, abnormalities of global left ventricular function and regional wall motion occurred earlier during exercise, were of greater extent at peak exercise, and persisted longer after exercise than in the 11 patients with one and two vessel disease or the seven with normal coronary arteries. Although there were significant differences between the groups in absolute change in ejection fraction and the rate of change in ejection fraction related to exercise duration and heart rate, a considerable overlap of values between groups precluded the accurate prediction of coronary anatomy in individuals.

These data suggest that the amount of myocardium at risk from ischaemia in some patients with one and two vessel disease may resemble that in patients with three vessel disease. This study shows that an anatomical classification based solely on the number of diseased vessels will not predict the extent of the impairment of left ventricular function on exercise.

Patients with coronary artery disease develop impairment of left ventricular function on exercise, and the extent of this dysfunction can be assessed by radionuclide angiography. ${ }^{12}$ Peak exercise is necessary to maximise the sensitivity of both the first pass and gated equilibrium techniques. ${ }^{34}$ It may be, however, that imaging at stages before and after peak exercise could increase the diagnostic precision.

Recent data from exercise electrocardiography have suggested that coronary anatomy can be accurately predicted by assessment of the changes in ST segments related to heart rate (the ST/HR slope) as an index of developing ischaemia. ${ }^{5}$ Since radionuclide angiography will estimate the degree of developing ischaemia by the changes in ejection

Requests for reprints to Dr J L Caplin, Department of Cardiology, St Bartholomew's Hospital, West Smithfield, London EC1A 7BE.

Accepted for publication 19 September 1985 fraction and regional left ventricular wall motion, it might be expected that a functional index derived from these data could predict the extent of coronary disease if such changes were solely related to the number of diseased vessels.

First pass radionuclide angiography can assess rapid changes in left ventricular function, and the development of gold-195m, ${ }^{6}$ a radioisotope with an ultra short half life, and its validation for use in $\operatorname{man}^{7}$ means that multiple rapid sequential studies of left ventricular function are now feasible. This study was designed to assess the time course of changes in left ventricular function during and after exercise and to see how this might be related to the anatomical extent of coronary artery disease.

\section{Patients and methods}

STUDY POPULATION AND EXCLUSIONS

Twenty five non-consecutive male patients were 
selected on the basis of their coronary anatomy. They had been referred to the cardiac department for assessment of chest pain and had the usual clinical indications for coronary angiography. All were in sinus rhythm, no patient had clinical congestive cardiac failure, and those with an impaired resting ejection fraction $(<40 \%)$ were excluded. Patients with evidence of previous myocardial infarction were not excluded provided their resting ejection fraction was $\geqslant 40 \%$.

\section{CORONARY ARTERIOGRAPHY}

Cardiac catheterisation was performed within two months of the radionuclide study by either the Sones's or Judkins's techniques. The coronary anatomy was assessed by an experienced observer who did not know the result of the radionuclide study. Multiple views of each coronary artery were assessed and the extent of "surgically" important disease (luminal narrowing $>50 \%$ ) in one or more major arteries was noted. On this basis the patients were assigned to groups with $(a)$ normal coronaries, $(b)$ one and two vessel disease, and $(c)$ three vessel disease. No subject in the group with normal coronaries had any obstructive lesions. In addition the coronary anatomy was assessed by means of a weighted coronary index ${ }^{8}$ with a score of 1 being normal and a progressive decline to 0 as obstruction increased.

\section{RADIONUCLIDE ANGIOGRAPHY}

All antianginal medications except sublingual nitrates were discontinued for at least $\mathbf{4 8}$ hours before the study; beta adrenergic antagonists were discontinued for at least $\mathbf{7 2}$ hours before the study..$^{10}$ Exercise first pass radionuclide angiography was performed in the upright anterior posterior projection with a Baird Atomic System 77 multicrystal gamma camera. ${ }^{11}$ An 18 gauge cannula was inserted into a large vein in the antecubital fossa and for each imaging point $15-20 \mathrm{mCi}$ (550-750 MBq) of gold-195m was injected by means of a rapid $20 \mathrm{ml}$ saline solution flush. The portable mercury-195m/gold-195m generator (AERE, Harwell, England) has been described elsewhere. ${ }^{6}$ Data were collected for $30 \mathrm{~s}$ with $30 \mathrm{~ms}$ framing intervals, and they were corrected for instrument dead time, crystal non-uniformity by means of a mercury-203 uniform flood, and rapid decay of the isotope.

Left ventricular ejection fraction was calculated from high frequency time-activity curves by a semiautomated technique. Regional wall motion was derived trom count-based regional ejection fraction images. ${ }^{12}$ Each image was assessed by an experienced observer who was unaware of the results of the coronary angiogram. The ventricle was visually divided into three equal segments-inferior, apical, and anterior. Regional wall motion was displayed by means of a 16 point colour scale for $100 \%$ to $0 \%$, each colour representing $6.25 \%$, and a segment was deemed to be abnormal if at least half of its border had a regional ejection fraction of $<50 \%{ }^{11}$

\section{EXERCISE PROTOCOL}

Patients performed maximal graded bicycle exercise in the upright position on an hydraulically braked bicycle ergometer (Fitron). Patients were imaged at rest and then started to cycle at a workload of $400 \mathrm{kpm} /$ minute $(67 \mathrm{~W})$ and this was increased by $200 \mathrm{kpm} /$ minute $(33 \mathrm{~W})$ every two minutes until peak exercise was reached. Patients were imaged at 3 minutes, at 6 minutes, and then at peak exercise. They were then instructed to continue exercise at as high a workload as possible for a further 2 minutes and they were then imaged as they stopped cycling immediately after exercise. They were then imaged again 2 minutes after exercise. The electrocardiogram (lead II) was monitored throughout the test and pulse rate and cuff arterial pressure were measured at each imaging point.

\section{RADIATION DOSIMETRY}

Subjects who completed the entire study received a maximum of six boluses of gold-195m (approximately $4500 \mathrm{MBq}$ ). We have assessed the radiation burden for this level of exposure from the Harwell mercury- $195 \mathrm{~m} /$ gold $-195 \mathrm{~m}$ generator to be 150 mrem to the kidneys, 17 mrem to the gonads, and 35 mrem to the whole body, based on a mercury-195 breakthrough of $<0.01 \%$. The equivalent burden from $1800 \mathrm{MBq}$ of technetium- $99 \mathrm{~m}$, as pertechnetate, which would be sufficient for only three studies, is 3500 mrem to the kidneys and 350 mrem to the whole body.

\section{STATISTICAL METHODS}

Statistical analysis was performed by the paired Student's $t$ test and Wilcoxon matched pairs signed ranks test to compare changes within a group, and the Mann-Whitney $U$ tests and $\chi^{2}$ test, as appropriate, for comparisons between groups. A p value of $<0.05$ was regarded as significant.

\section{Results}

AGE AND HAEMODYNAMIC VARIABLES AT REST AND ON EXERCISE

Table 1 shows the means (SD) of the ages and haemodynamic variables in each of the groups. The ages of the groups were not significantly different, and the only haemodynamic difference between groups was that peak exercise heart rate was significantly lower in those with three vessel disease than in the 
Table 1 Rest and peak exercise characteristics (mean (SD)) of the groups

\begin{tabular}{|c|c|c|c|c|c|c|c|c|}
\hline & $\begin{array}{l}\text { Age } \\
(y r)\end{array}$ & $\begin{array}{l}R H R \\
(b p m)\end{array}$ & $\begin{array}{l}R S B P \\
\left(m m H_{g}\right)\end{array}$ & $\begin{array}{l}R D P \\
\left(\times 10^{-2}\right)\end{array}$ & $\begin{array}{l}E x H R \\
(b p m)\end{array}$ & $\begin{array}{l}E x S B P \\
\left(m m H_{g}\right)\end{array}$ & $\begin{array}{l}E x D P \\
\left(\times 10^{-2}\right)\end{array}$ & $\begin{array}{l}\text { Ex Dur } \\
\text { (min) }\end{array}$ \\
\hline $\begin{array}{l}\text { Normal coronaries } \\
1+2 \text { vessel disease } \\
3 \text { vessel disease }\end{array}$ & $\begin{array}{l}49(10) \\
53(5) \\
50(6)\end{array}$ & $\begin{array}{l}78(17) \\
85(15) \\
69(12)\end{array}$ & $\begin{array}{l}124(16) \\
144(33) \\
137(21)\end{array}$ & $\begin{array}{r}96(20) \\
124(41) \\
95(27)\end{array}$ & $\begin{array}{l}161(13) \\
148(22) \\
140(27)^{\star}\end{array}$ & $\begin{array}{l}174(24) \\
187(38) \\
172(22)\end{array}$ & $\begin{array}{l}282(56) \\
280(76) \\
242(61)\end{array}$ & $\begin{array}{l}7 \cdot 2(1 \cdot 6) \\
5 \cdot 8(1 \cdot 1)^{\star} \\
5 \cdot 1(1 \cdot 8)^{\star}\end{array}$ \\
\hline
\end{tabular}

* 0.05 vs those with normal arteries.

R, rest; Ex, peak exercise; HR, heart rate; SBP, systolic blood pressure; DP, double product of heart rate $\times$ blood pressure; Dur, duration.

group with normal coronary arteries $(p<0.05)$. There was, however, no significant difference in the double products or the change in heart rates between the groups. Not surprisingly the main difference between the groups was in the duration of exercise. Patients without important coronary disease were able to exercise for significantly longer than those with coronary disease $(p<0.05)$. Five of the seven with normal coronary arteries but only six of 18 with coronary disease could exercise for 6 minutes or more.

The mean coronary score in the subjects with coronary artery disease was $0.41(0.20)$ and ranged from 0.09 to 0.7 . The score for the one and two vessel group was $0.48(0.16)$ and for the three vessel group it was $0.29(0.20)(p<0.05)$.

SERIAL CHANGES IN EJECTION FRACTION DURING EXERCISE AND AFTER EXERCISE

Figure 1 shows the mean left ventricular ejection

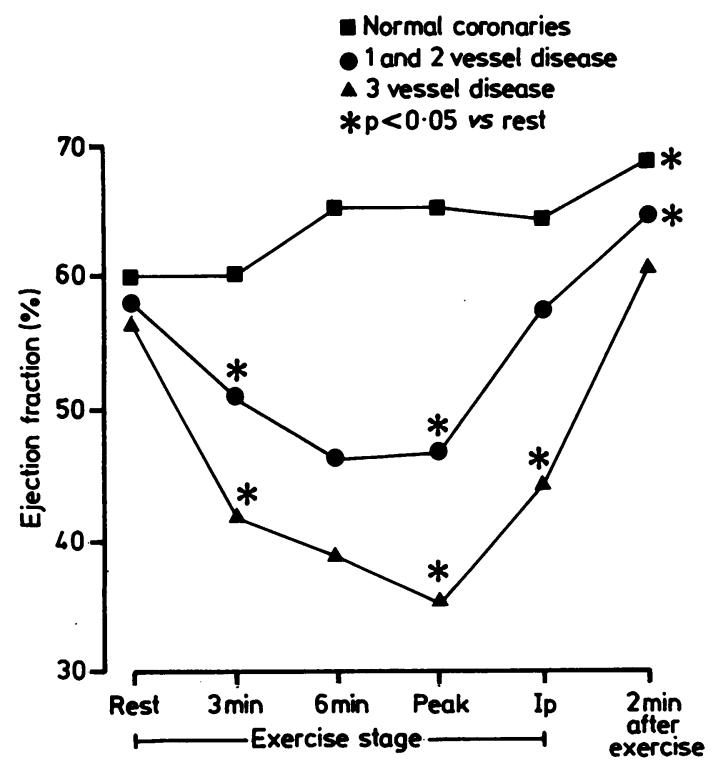

Fig. 1 Mean ejection fraction of the three groups at each stage. I $p$, immediately after exercise. fractions in each group at various imaging stages. In those with normal coronary arteries mean ejection fraction was maintained and tended to rise during exercise. Ejection fraction at rest was 60 (3)\% (mean (SD)) and rose to $65(10) \%$ at peak exercise (p, not significant). Two minutes after exercise the ejection fraction $(68(6) \%)$ significantly $(p<0.01)$ exceeded the resting value.

In the group with one and two vessel disease the ejection fraction fell during exercise with maximum depression occurring at peak exercise $(58(10) \%$ vs $47(10) \%, p<0.01)$. Mean ejection fraction had returned to the resting level as the patient stopped cycling, immediately after exercise; and by two minutes after exercise the ejection fraction had significantly rebounded above the resting level to $64(8) \%(p<0.05)$. Nine of the subjects showed this response.

The group with three vessel disease, like those with one and two vessel disease, showed significant falls in ejection fraction on exercise, again with the maximum fall at peak exercise $(57(12) \%$ vs $35(8) \%$, $p<0.001)$. In contrast with the group with one and two vessel disease the ejection fraction remained depressed immediately after exercise (44(9)\%) ( $p<0.05$ vs rest), and there was no significant rebound increase in ejection fraction in this group two minutes after exercise. A typical example of the images in this group is shown in Fig. 2. At any given stage the depression in ejection fraction was greater in the group with three vessel disease than in the group with one and two vessel disease.

Table 2 shows the mean (SD) of the ejection fractions at all the stages in each of the groups. As discussed above there were significant intragroup changes during and after exercise when compared with the resting level. There was no significant difference in the resting ejection fractions between groups. On exercise, however, ejection fraction was significantly depressed in the patients with coronary disease when compared with those without. Immediately after exercise only those with three vessel disease were different from those without coronary disease. Their mean ejection fraction was also significantly lower than that in the group with one and two vessel disease. There was no significant 


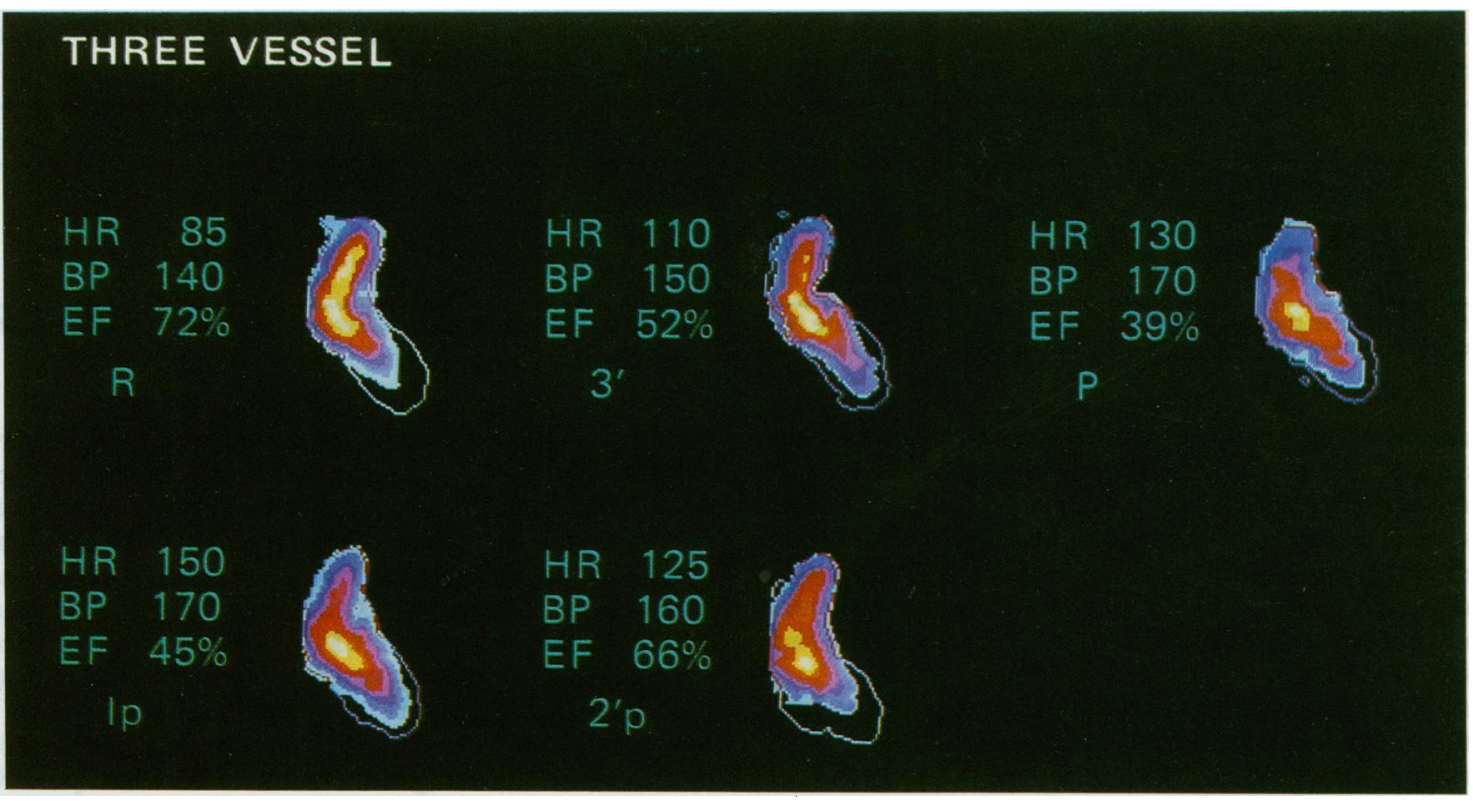

Fig. 2 Studies in a patient with three vessel disease. The images show the end diastolic perimeter enclosing the end systolic image. $H R$, heart rate; $B P$, blood pressure; $E F$, ejection fraction. $R$, rest; $3^{\prime}, 3$ minutes exercise; $P$, peak exercise; I , immediately after exercise; $2^{\prime} p, 2$ minutes post-exercise.

difference between the groups 2 minutes after exercise. At peak exercise patients with three vessel disease also had a significant reduction in ejection fraction compared with those who had one and two vessel disease.

An abnormal ejection fraction response was defined as a fall in ejection fraction of $\geqslant 5 \%$ below the value at rest. Table 3 shows the proportion of patients in each group who had an abnormal response. Only one of the patients with normal coronaries had an abnormal response and this was a transient fall of $5 \%$, from $63 \%$ to $58 \%$ after 3 minutes of exercise. Subsequently his ejection fraction returned to the level at rest. In contrast a large proportion of patients with coronary disease had abnormal responses, and this was related to the extent of the disease. The intergroup difference in proportion of patients with an abnormal response at the various stages is as shown. Patients with one and two vessel disease had a significantly higher proportion of abnormal responses at 6 minutes, at peak exercise, and immediatly after exercise than patients with normal coronaries. In the group with three vessel disease the difference was significant at 3 minutes, peak exercise, and immediately after exercise, suggesting that abnormalities in global left ventricular function tended to occur earlier in this group than in those with one and two vessel disease.

\section{CHANGES IN REGIONAL WALL MOTION DURING AND AFTER EXERCISE}

Table 4 shows the proportion of abnormal segments at each of the imaging stages. At rest one of the seven with normal coronary arteries had a single segmental abnormality, whereas five of the 11 with one and two vessel disease had abnormal segments, and four of seven with three vessel disease had a single segmental abnormality ( $p$ not significant).

Table 2 Ejection fractions (means (SD)) in the groups at various stages of exercise

\begin{tabular}{|c|c|c|c|c|c|c|}
\hline & \multirow[t]{2}{*}{ Rest } & \multicolumn{3}{|l|}{ Exercise } & \multicolumn{2}{|l|}{ After exercise } \\
\hline & & $3 \min$ & $6 \min$ & Peak & Immediately & $2 \min$ \\
\hline $\begin{array}{l}\text { Normal coronaries } \\
1+2 \text { vessel disease } \\
3 \text { vessel disease }\end{array}$ & $\begin{array}{l}60(3) \\
58(10) \\
57(11)\end{array}$ & $\begin{array}{l}60(6) \\
51(10)^{\star} \dagger \\
42(9)^{\star} \dagger\end{array}$ & $\begin{array}{l}65(9) \\
46(12) \dagger \\
39(1) \dagger\end{array}$ & $\begin{array}{l}65(10) \\
47(10)^{\star}+ \\
35(8)^{\star+t}\end{array}$ & $\begin{array}{l}64(6) \\
57(11) \\
44(9)^{\star}+t\end{array}$ & $\begin{array}{l}68(6)^{\star} \\
64(8)^{\star} \\
61(10)\end{array}$ \\
\hline
\end{tabular}

${ }^{\star} \mathrm{p}<0.05$ vs rest value (paired $t$ test); $\nmid \mathrm{p}<0.05$ vs normal and $\ddagger \mathrm{p}<0.05$ vs $1+2$ vessel disease (Mann-Whitney $U$ test). 
Table 3 Proportion of subjects in each group with an abnormal ejection fraction response (fall of $\geqslant 5 \%$ ) to exercise at each stage compared with rest

\begin{tabular}{llll}
\hline Stage & Normal coronaries & $1+2$ vessel disease & 3 vessel disease \\
\hline 3 min exercise & 0.14 & 0.45 & $0.71^{\star}$ \\
6 min exercise & 0.00 & $0.66^{\star}$ & 1.00 \\
Peak exercise & 0.00 & $0.73^{\star}$ & $1.00^{\star}$ \\
Immediately after exercise & 0.00 & $0.45^{\star}$ & $0.71^{\star}$ \\
2 min after exercise & 0.00 & 0.00 & 0.14 \\
\hline
\end{tabular}

At 6 min exercise the result for those with three vessel disease fails to reach statistical significance; however, the number of subjects who reached that stage was small. ${ }^{\star} \mathrm{p}<0.05$ vs normal coronaries $\left(\chi^{2}\right.$ test).

At 3 minutes of exercise the seven with normal coronary arteries had developed a total of six abnormal segments, whereas the 11 with one and two vessel disease had developed 16 segmental abnormalities ( $p$ not significant $v s$ normal), and the seven with three vessel disease had developed 16 abnormalities $(\mathrm{p}<0.01$ vs normal, $\mathrm{p}<0.05$ vs one and two vessel disease).

At 6 minutes and at peak exercise segmental abnormalities present early in exercise in those with normal coronary arteries tended to resolve, such that only three segments remained abnormal at peak. In contrast, in the subjects with coronary disease segmental abnormalities invariably became worse during exercise ( $p<0.01$ vs normal arteries). In the group with one and two vessel disease there were segmental abnormalities at peak exercise in all but one patient and only one other had less than two abnormal segments. In those with three vessel disease all segments except one were abnormal at peak exercise. Immediately after exercise, despite the return of the mean ejection fraction to control levels in the one and two vessel group, segmental wall motion abnormalities were present in seven of 11 subjects and this result was significant $(p<0.01)$ when compared with the group with normal coronary arteries. All the group with three vessel disease showed persistent wall motion abnormalities immediately after exercise and in three subjects these persisted after 2 minutes' recovery. One of these subjects, who subsequently was found to have a left main stem stenosis in addition to three vessel disease, had persistence of segmental abnormalities in three segments.

In the groups without three vessel disease, there were fewer segmental abnormalities after exercise than before it. This pnenomenon, improvement in resting wall motion abnormalities after exercise, has been reported before. ${ }^{13}$

RELATION BETWEEN THE DERIVED RATES OF CHANGE IN LEFT VENTRICULAR FUNCTION AND THE EXTENT OF CORONARY DISEASE Two indices of rates of change in left ventricular function during exercise were derived. The first was a relatively simple measure of total change in ejection fraction from rest to peak exercise divided by the exercise duration-this gave an overall rather than an "instantaneous" rate of change. Figure 3 shows the results of these calculations for each group. The rates were $0.631(0.982) \% / \mathrm{min}$ for those with normal coronary arteries, $-2.09(1.78) \% / \mathrm{min}$ for those with one and two vessel disease $(p<0.01$ vs normal), and $-4.76(2.88) \% / \mathrm{min}$ for those with three vessel disease $(p<0.001$ vs normal and $p<0.05$ vs one and two vessel disease). Although there were highly significant differences between the groups there is considerable overlap, particularly between

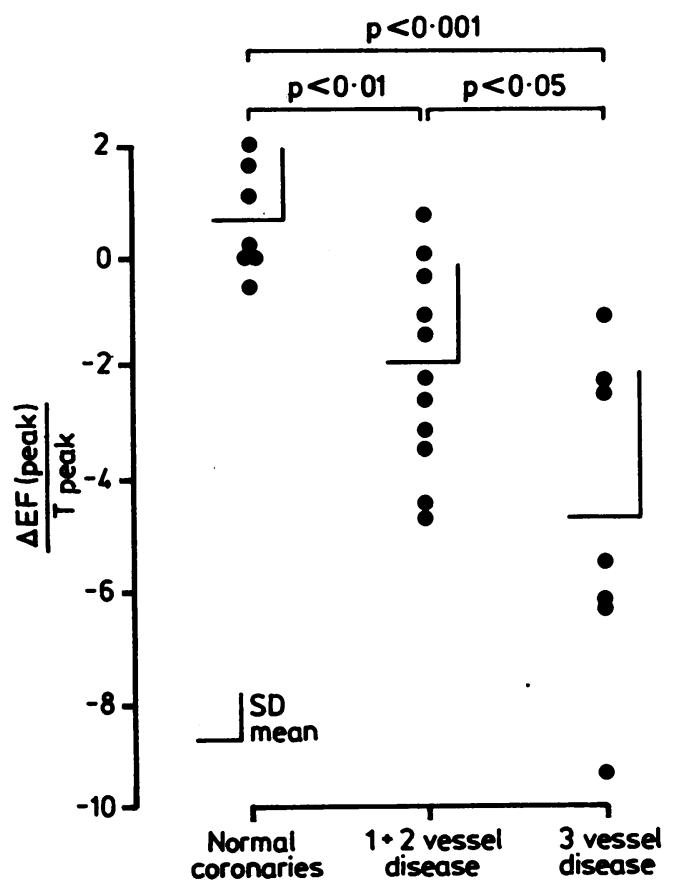

Fig. 3 Rate of change of ejection fraction to peak exercise $(\triangle E F($ Peak)/T peak) in the three groups. Means, $S D$, and $p$ values are shown. 
Table 4 Proportion of abnormal ventricular regional segments at each of the imaging stages in the three groups

\begin{tabular}{lllc}
\hline Stage & Normal coronaries & $1+2$ vessel disease & 3 vessel disease \\
\hline Rest & 0.05 & 0.18 & 0.19 \\
3 min exercise & 0.29 & 0.48 & $0.76^{\star} \dagger$ \\
6 min exercise & 0.20 & $0.67 \star$ & $1.07^{\star}$ \\
Peak exercise & 0.14 & $0.73^{\star}$ & $0.95^{\star} \dagger$ \\
Immediately after exercise & 0.05 & $0.39 \star$ & $0.71^{\star} \dagger$ \\
2 min after exercise & 0.00 & 0.06 & $0.24^{\star}$
\end{tabular}

The left ventricle was divided into three equal segments (inferior, apical, and anterior) and these were deemed to be abnormal if over half of the border had a regional ejection fraction of $<50 \%$. ${ }^{\star} p<0.05$ vs normal; $\nmid p<0.05$ vs $1+2$ vessel disease $\left(\chi^{2}\right.$ test).

those with normal coronary arteries and those with one and two vessel disease and between those with one and two vessel disease and those with three vessel disease. One of the results in the group with three vessel disease was considerably more negative than the others and this may have biased the mean leading to a spurious significant difference when these results were compared with those in patients with one and two vessel disease.

We examined another index of rate of change of ejection fraction. This was the relation between the rate of change in heart rate derived for each stage of

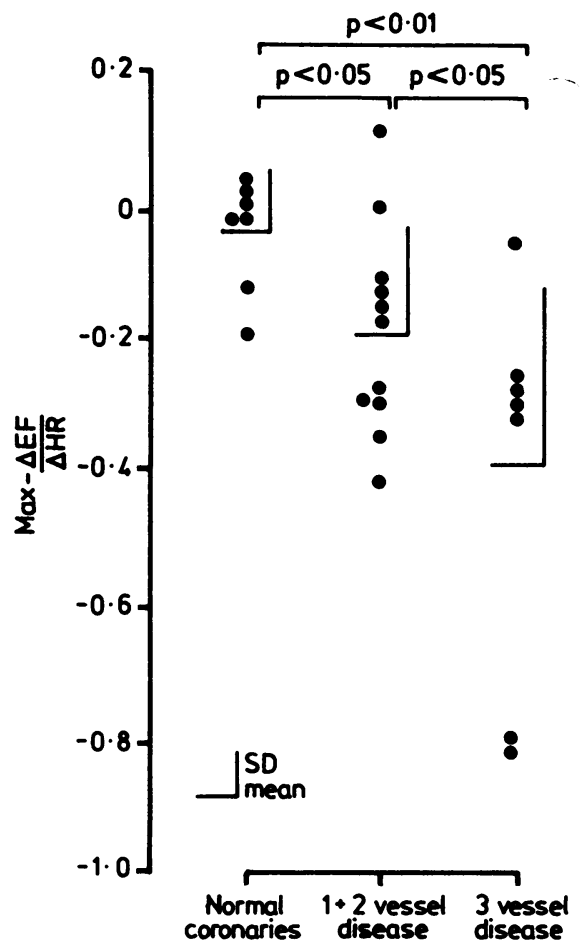

Fig. 4 Maximum negative (or minimum positive) change of ejection fraction related to change of heart rate $(\triangle E F / \triangle H R$ ) in the three groups. Means, $S D$, and $p$ values are shown. exercise and the maximum negative or minimum positive value noted for each subject. This particular index was chosen because it resembles the ST/HR slope used by some investigators for analysis of exercise electrocardiograms to determine the extent of coronary disease. The rates were $0.0122(0.0736) \% / \mathrm{bpm}$ for those with normal coronary arteries, $-0 \cdot 19(0 \cdot 156) \% / \mathrm{bpm}$ for those with one and two vessel disease ( $p<0.05$ vs normal), and $-0.407(0.286) \% / \mathrm{bpm}$ for those with three vessel disease $(p<0.01$ vs normal and $p<0.05$ vs one and two vessel disease) (Fig. 4). As with the first index, although there were significant differences between the groups, the degree of overlap would preclude the use of either algorithm to predict accurately the extent of coronary disease in individuals.

Both indices were also compared with the coronary score in those subjects with coronary artery disease. There was no significant correlation between the coronary score and either index. In addition the coronary score was not related to exercise duration or change in ejection fraction. To see whether the coronary score in itself was a better predictor of functional change on exercise we examined the results in two groups-those with a high score of $>0.4(n=10)$ and those with a low score of $<0.4$ $(n=8)$. There was no significant difference in overall change in ejection fraction at peak exercise in the two groups $(-14(11) \%$ in the high group versus $-17(11) \%$ in the low group). The values for the first index were $-2 \cdot 8(2 \cdot 4) \% / \mathrm{min}$ for high group and $-3.5(2.9) \% / \mathrm{min}$ in the low group ( $p$ not significant). For the second index the corresponding figures were $-0.26(0.24) \% / \mathrm{bpm}$ and $-0.29(0.24) \% / \mathrm{bpm}$ respectively ( $\mathrm{p}$ not significant).

\section{Discussion}

Radionuclide angiography is an accepted method for the assessment of patients with chest pain and suspected coronary artery disease. ${ }^{12}$ Although coronary angiography is the universally accepted standard by which non-invasive techniques are judged, it has its limitations. First it is an invasive technique that may cause morbidity and mortality, ${ }^{14}$ and 
seondly it provides information about anatomy rather than function.

Exercise testing in patients with coronary disease produces impairment of left ventricular function which reflects the extent of ischaemia. Therefore non-invasive methods that can quantity changes in left ventricular function provide information on the magnitude and rate of development of ischaemia.

It is possible to study left ventricular function at various stages of exercise by means of equilibrium gated radionuclide angiography, but the time required for data acquisition, two minutes at least, will blur any rapid changes. First pass studies, in which transit of radioisotope through the left heart lasts for only a few seconds, can be used to assess rapid changes in left ventricular function, but an injection of radioisotope is required at each imaging point. Thus radiation exposure constrains the number of injections to a maximum of three per study of conventional technetium- $99 \mathrm{~m}$ based radiopharmaceuticals. The development of radiopharmaceuticals with ultrashort half 1 ifes ${ }^{6}$ has meant that not only the extent, but also the time course of changes in function on exercise may be studied. If the magnitude or rate of development of functional impairment were directly related to the coronary anatomy it might be possible to predict the extent of coronary disease by examining the time course of these changes.

In this study a group of patients who had a clinical indication for coronary angiography and relatively preserved resting left ventricular function were studied by multiple rapid sequential first pass radionuclide angiography with gold- $195 \mathrm{~m}$. There were no significant differences in terms of age, resting ejection fraction, and resting and exercise haemodynamics between patients with normal coronary arteries and those with mild or severe coronary disease. Subjects with normal coronary arteries exercised for significantly longer than those with coronary disease, and they tended to maintain or increase their ejection fraction throughout exercise, with a significant rebound of ejection fraction above the level at rest after exercise. This rebound has been previously documented both after bicycle ${ }^{315}$ and treadmill exercise, ${ }^{16}$ and is thought to be due to sudden reductions in afterload and heart rate on cessation of exercise coupled with a maintained metabolic requirement that leads to an increase in stroke volume and hence ejection fraction. ${ }^{3}$

In patients with one and two vessel disease there was a significant fall in ejection fraction on exercise with the maximum fall being at peak exercise. In this group there was a rapid return of ejection fraction to the resting level immediately after exercise and a rebound above the rest level at two minutes.
In the group with three vessel disease, ejection fraction fell throughout exercise. Again the fall was maximal at peak exercise. In this group the fall in ejection fraction was greater at each stage than in those with one and two vessel disease. These patients still showed abnormalities after exercise and some of the group were abnormal even after two minutes of recovery.

These data suggested that patients with varying degrees of coronary obstruction could be distinguished by their ejection fraction response to exercise, but there was some overlap between the groups. The rebound in ejection fraction during recovery noted above seems unrelated to the type of exercise since it has been reported for supine ${ }^{15}$ and upright bicycle exercise ${ }^{3}$ and treadmill exercise. ${ }^{16}$ Furthermore, lack of rebound seems to be associated with an increased likelihood of ischaemic pain during exercise and, as confirmed by this study, more extensive coronary disease.

Further assessment of regional wall motion also showed significant differences between the groups. Subjects with three vessel disease tended to develop segmental abnormalities early and these persisted longer after exercise than in the other groups. Again despite these significant differences the overlap in results in the individual subjects precludes definite anatomical diagnosis.

These data suggested that subjects with more extensive coronary artery disease had a greater likelihood of developing changes in global ejection fraction or regional wall motion early in exercise than subjects with less severe disease. This complements a previous study of exercise electrocardiography in which a positive test occurring early during exercise has been shown to be associated with more extensive coronary artery disease and a worse outcome. ${ }^{17}$ Thus the rate of change in ejection fraction might allow better discrimination of the extent of coronary disease than the overall change in ejection fraction at peak exercise. Because of this we also assessed two indices of the rate of change in ejection fraction. In the first a measure of the overall rate of change of ejection fraction was derived. This showed that there were significant differences between the groups but that there was considerable overlap of individual values.

The second index related the maximum fall in ejection fraction to changes in heart rate. This was chosen to be analogous to the exercise electrocardiographic ST/HR slope that has been reported to predict coronary anatomy by some workers ${ }^{5}$ but not others. ${ }^{18}$ Although there were significant differences between the groups, again there was a considerable overlap of values. The relation between these indices and a widely used coronary score $^{8}$ 
again failed to predict the extent of coronary disease.

The data from both these indices (Figs. 3 and 4) show that there is a general relation between the extent of coronary artery obstruction and the degree of functional impairment on exercise. The extent of overlap between those with severe and less severe coronary artery disease is not surprising. If the degree of ischaemia were related solely to the number of diseased vessels, ignoring the vessel dominance, number, site, severity and length of the lesions, and the presence of collaterals, this would be an example of almost unique biological homogeneity. ${ }^{19}$

The first index, which relates change in ejection fraction to exercise duration, may be suitable for use in studies in which gold- $195 \mathrm{~m}$ is not available. It may be that further studies will extend the accuracy of this index by generation of an algorithm relating it to the anatomical extent of coronary disease. The second index, which is based on heart rate change, may also be adapted to conventional studies, and it might be of use when the heart rate response is attenuated as it is in subjects who are unable to exercise maximally. Both indices may also be of use in the more accurate assessment of myocardium in jeopardy from ischaemia. Indeed outcome in patients with coronary artery disease is more closely related to an index of coronary artery jeopardy, and hence myocardium at risk, than to the number of diseased vessels. ${ }^{20}$

The failure of any of these direct or derived indices of changing left ventricular function on exercise to predict accurately the number of diseased coronary vessels suggests a discrepancy between functional and anatomical assessments of the extent of ischaemic heart disease. Because changes in ejection fraction on exercise are affected not only by the development of ischaemia but also by changes in preload and afterload there are reservations about the usefulness in the diagnosis of coronary disease of a single measure of left ventricular ejection fraction during exercise. None the less an assessment of the amount of myocardium at risk remains the single most prognostically useful measurement in these patients. $^{21}$

Prognosis in patients with three vessel disease can be altered by coronary artery bypass surgery, ${ }^{22}$ and indeed the present study has shown that as a group these patients do have more myocardium at risk from ischaemia. In some patients with three vessel disease, however, left ventricular function on exercise is preserved, and in such patients the prognosis without surgery is good. ${ }^{21}$ It may be that those who have less than three vessel disease but who have functional impairment similar to those with three vessel disease are at higher risk and would therefore benefit from revascularisation. This hypothesis requires further study. Data to support this have come from a long term prospective trial of coronary artery surgery which suggested that the long term outcome in some patients with two vessel disease is similar to that in patients with three vessel disease. ${ }^{23}$ If this is subsequently confirmed then the noninvasive assessment of left ventricular function at rest and exercise may, in the future, be as important as coronary anatomy in the selection of patients who will benefit from coronary surgery.

Dr Caplin is supported by the British Heart Foundation.

\section{References}

1 Borer JS, Bacharach SL, Green MV, Kent KM, Epstein SE, Johnston GS. Real-time radionuclide cineangiography in the non-invasive evaluation of global and regional left ventricular function at rest and during exercise in patients with coronary-artery disease. N Engl f Med 1977; 296: 839-44.

2 Berger HJ, Reduto LA, Johnstone DE, et al. Global and regional left ventricular response to bicycle exercise in coronary artery disease. $A m \mathcal{F} \mathrm{Med} 1979$; 66: 13-21.

3 Dymond DS, Foster C, Grenier RP, Carpenter J, Schmidt DH. Peak exercise and immediate postexercise imaging for the detection of left ventricular function abnormalities in coronary artery disease. $A m \mathcal{F}$ Cardiol 1984; 53: 1532-7.

4 Brady TJ, Thall TH, Lo K, Pitt B. The importance of adequate exercise in the detection of coronary heart disease by radionuclide ventriculography. $\mathcal{F} \mathrm{Nucl}$ Med 1980; 21: 1125-30.

5 Elamin MS, Boyle R, Kardash MM, et al. Accurate detection of coronary heart disease by new exercise test. Br Heart f 1982; 48: 311-20.

6 Elliot AT, Dymond DS, Stone DL, et al. A mercury$195 \mathrm{~m} /$ gold-195m generator for use in first-pass nuclear angiocardiography. Phys Med Biol 1983; 28: 139-47.

7 Dymond DS, Elliot AT, Flatman W, et al. The clinical validation of gold-195m: a new short half-life radiopharmaceutical for rapid sequential first-pass angiocardiography in patients. $\mathcal{F}$ Am Coll Cardiol 1983; 2: 85-92.

8 Balcon R, Cattell MR, Stone DL, Fuerlicht J. A computer generated index for the assessment of coronary angiography. Acta Med Scand 1978; 615 (suppl): 25-30.

9 Myers JH, Horwitz LD. Haemodynamic and metabolic response after abrupt withdrawal of long-term propranolol. Circulation 1978; 58: 196-201.

10 Lindenfield J, Crawford MH, O'Rourke RA, Levine SP, Montiel MM, Horwitz LD. Adrenergic responsiveness after abrupt propranolol withdrawal in normal subjects and in patients with angina pectoris. Circulation 1980; 62: 704-11. 
11 Dymond DS, Jarritt PH, Britton KE, Spurrell RAJ. Detection of postinfarction left ventricular aneurysms by first pass radionuclide ventriculography using a multicrystal gamma camera. Br Heart $f$ 1979; 41: 68-78.

12 Maddox DE, Holman BL, Wynne J, et al. Ejection fraction image: a noninvasive index of regional left ventricular wall motion. Am f Cardiol 1978; 41: 1230-8.

13 Seaworth JF, Higginbotham MB, Coleman RE, Cobb FR. Effect of partial decreases in exercise work load on radionuclide indexes of ischemia. $\mathcal{F} \mathrm{Am}$ Coll Cardiol 1983; 2: 522-9.

14 Grossman W. Complications of cardiac catheterization: incidence, causes and prevention. In: Grossman W, ed. Cardiac catheterization and angiography. 2nd ed. Philadelphia: Lea and Febiger, 1980: 25-35.

15 Pfisterer ME, Slutsky R, Schuler G, et al. Profiles of radionuclide left ventricular ejection changes induced by supine bicycle exercise in normals and patients with coronary heart disease. Cathet Cardiovasc Diagn 1979; 5: 305-17.

16 Battler A, Slutsky R, Pfisterer M, Ashburn W, Froelicher V. Left ventricular ejection fraction change during recovery from treadmill exercise: a preliminary report of a new method for detecting coronary artery disease. Clin Cardiol 1980; 3: 14-8.
17 Schneider RM, Seaworth JF, Dohrmann ML, et al. Anatomic and prognostic implications of an early positive treadmill exercise test. Am $\mathcal{F}$ Cardiol 1982; 50: 682-8.

18 Balcon R, Brooks N, Layton C. Correlation of heart rate/ST slope and coronary angiographic findings. $\mathrm{Br}$ Heart f 1984; 52: 304-7.

19 Fox KM. Exercise heart rate/ST segment slope relation. Perfect predictor of coronary disease? $\mathrm{Br}$ Heart $\mathcal{F}$ 1982; 48: 309-10.

20 Califf RM, Phillips HR, Hindman MC, et al. Prognostic value of a coronary artery jeopardy score. $\mathcal{F} \mathrm{Am}$ Coll Cardiol 1985; 5: 1055-62.

21 Bonow RO, Kent KM, Rosing DR, et al. Exerciseinduced ischemia in mildly symptomatic patients with coronary-artery disease and preserved left ventricular function. $N$ Engl f Med 1984; 311: 1339-45.

22 The Veterans Administration Coronary Artery Bypass Surgery Cooperative Study Group. Eleven-year survival in the Veterans administration randomized trial of coronary bypass surgery for stable angina. $N$ Engl $f$ Med 1984; 311: 1333-9.

23 European Coronary Surgery Study Group. Long-term results of prospective randomised study of coronary artery bypass surgery in stable angina pectoris. Lancet 1982; ii: 1173-80. 